\title{
A Contextual Learning Approach Based on Augmented Reality to Improve Students' Scientific Literacy
}

\author{
Yang Yang ${ }^{1}$ \\ Enrui Liu ${ }^{2}$ \\ Sining $\mathrm{He}^{3}$ \\ $\mathrm{Su} \mathrm{Cai}{ }^{4 *}$
}

\begin{abstract}
Inquiry activities are important and challenging in primary science classes since it is not only related to scientific knowledge, but also to scientific literacy. However, with consideration of limited cost and risk issues, most of optical experiments are insufficient to implement in primary schools, so that students should rely on their own imagination to understand abstract concepts without inquiry activities. In this study, a contextual learning approach based on augmented reality (AR) technology was proposed to cope with this problem. A specially developed AR system created a virtual-reality combined environment for students taking an optical inquiry task about rainbow in grade 5. Moreover, a mixed methods research approach was used to analyze understanding about scientific concepts, use of inquiry process skills, and higher order thinking skills of the students who learned with the proposed approach. The experimental results revealed that the learning approach based on AR was able to assist in the construction of understandings about scientific concepts, provide students opportunities to use inquiry process skills, and develop students' higher order thinking skills. Furthermore, by interviewing the teacher, the benefits and challenges of using this contextual learning approach based on AR were reported. These findings could be valuable references for those who intend to implement contextual inquiry learning activities with AR systems to assist improve students' scientific literacy effectively.
\end{abstract}

Keywords : contextual learning, augmented reality, Inquiry activities, scientific literacy

\section{Introduction}

In recent years, science has been paid more and more attention on children's education filed. Science literacy has been regarded as one of the most important qualities that needed to be improved from one's childhood. Inquiry activities play a significant role in science courses to meet

1. Graduate, School of Educational Technology, Faculty of Education, Beijing Normal University, China

2. Graduate, School of Educational Technology, Faculty of Education, Beijing Normal University, China 3. Undergraduate, School of Educational Technology, Faculty of Education, Beijing Normal University, China

4. Associate professor, School of Educational Technology, Faculty of Education, Beijing Advanced Innovation Center for Future Education, Beijing Normal University

https://doi.org/10.34097/jeicom_1_1_2 
the outcomes that make students not only acquire science knowledge but also develop science literacy.

However, it is not easy to carry out inquiry activities in a real class. The equipment of many experiments is so rare and expensive, that schools should take on a lot of expense to get and maintain it. Even though a school owns the equipment, the number of equipment usually won't be enough for every student to have the opportunity to experience. Besides, there are some experiments with risk factors always been cancelled, for teachers would be worried about students' operation. So interesting and worthwhile inquiry activities are difficult to implement in primary school.

Augmented Reality (AR) has been used to support students' scientific inquiry these years, and related researches have shown that the combination of AR and some instructional strategies, such as textual scaffold, collaborative scaffold and repertory grid, is able to synergistically guide students in learning process and improve their learning motivation and performance (Tarng, Ou, Lu, Shih, \& Liou, 2018; Wu, Hwang, Yang, \& Chen, 2018; Yoon, Anderson, Park, Elinich, \& Lin, 2018). And some other studies have shown that AR plays a significant role in enhancing students' critical thinking tendency (Chang \& Hwang, 2018), group self-efficacy (Chang \& Hwang, 2018), concepts constructions (Enyedy, Danish, \& DeLiema, 2015) and deeper understanding (Hsiao, Chang, Lin, \& Wang, 2016).

In this study, we used a contextual learning approach to adapt the learning environment with $\mathrm{AR}$ in a fifth-grade science lesson. Moreover, a mixed methods research approach was used to analyze if activities in class effectively improve students' scientific literacy.

\section{Literature Review}

\subsection{Augmented Reality}

Augmented reality is a technology that supplements the real world with virtual objects and appears to coexist in the real world. A system based on AR is defined to have the following properties:(1) combines real and virtual objectives in a real environment;(2) runs interactively and synchronously; and (3) aligns real and virtual objects with each other(Azuma et al., 2001; Rt, 1997). By 2010, AR was seen in advertising, education, navigation, and information(Carmigniani, 2011). At first, AR has been used to provide more information for learning activities, and it was more widely used in sightseeing and museum guidance (Bruns, Brombach, Zeidler, \& Bimber, 2007; Dunleavy, Dede, \& Mitchell, 2009; Liu \& Wang, 2009; Miyashita et al., 2008). Since then, the role of AR in museums and science museums has attracted researchers' attention.

Early studies took advantage of AR's character, such as visualizing invisible phenomena, to create better inquiry environments for students when visiting museums. Asai, Sugimoto, and Billinghurst (2010) superimposed the lunar surface in a real environment with AR in a science museum, which effectively inspired the collaboration between parents and their children. Takahashi, Takahashi, Kusunoki, Terano, and Inagaki (2013) presented more text information according to objects with AR to guide visitors, and the found it aroused visitors' interest and promote them construct knowledge. Yoon and Wang (2014) took on the current magnetic field according to the position of appointed objects and conclude AR's roles in science museums. They thought AR could (1) offer inquiry environments, (2) enhance students' comprehension, and (3) promote more expressions and consistency in collaboration.

Some later researches began to focus on the performance of other tools or strategies in AR inquiry environments. Heather Toomey Zimmerman et al. (2015) found that students' 
understanding of concepts could be enhanced by coordinating images with actual samples. Wernhuar, Yu-Sheng, Chiu-Pin, and Kuo-Liang (2016) showed that combined with GPS, electronic compass, triaxial accelerometer or other sensors on mobile devices, AR applications could create a richer inquiry environment and provide more functions to support students' learning activities. Chen, Chou, and Huang (2016) claimed students' would have better performance if they used not only AR application but also concept map in inquiry activities. Wu, Hwang, Yang, and Chen (2018) pointed out the repertory grid into an AR application also could improve students' learning performance.

In recent years, sites that researchers attempted to use AR have been extended from museums to outdoors and classrooms. H. T. Zimmerman, Land, and Jung (2016) designed an AR application that can present biology information about trees based on trees' location in a botanical garden to study which factors can facilitate learning. Chang and Hwang (2018) used AR to guide students to operate in a flipped learning. Wu et al. (2018) brought AR into a classroom activity to help students know more information about butterflies based on their specimens.

In summary, AR has been paid much attention in primary science education for long years, and its potential in assisting in setting up inquiry environments has been revealed. However, previous studies often ignored the integration of AR-based activities into the daily teaching process. In this study, we used a specially developed learning approach to ensure the full use of AR.

\subsection{Contextual Learning Approach}

To fully take AR's advantages in inquiry activities in science teaching, a contextual learning approach can be implemented to control process. Contextual approaches are one kind of learning approaches that give a chance to construct the knowledge(Kusmayadi, Riyadi, Kartikaningtyas, \& Kusmayadi, 2017). As learning can be conceptualized as a contextually driven effort to make meaning in order to survive and prosper within the world(Falk \& Dierking, 2000), presenting essential information in the environment and inspiring learners to inquiry actively are the cores of a contextual learning approach, which are also very consistent with the characteristics of AR technology.

The 5E teaching model is a widely used and modified one among leaning approaches towards inquiry activities in science education(Bybee, 2014). BSCS(Biological Science Curriculum Study) in America put forward and developed the $5 \mathrm{E}$ model based on related theories of learning psychology and constructivism, which stated a learning sequence that can help students construct their understandings and come up with new ideas from experience(NASA, 2008). There are 5 activities in the sequence, engagement, exploration, explanation, elaboration and evaluation(NASA, 2008). To integrate AR technology well with science education, we developed a contextual learning approach by adjusting the 5E model based on contextual learning, as shown in Figure 1.

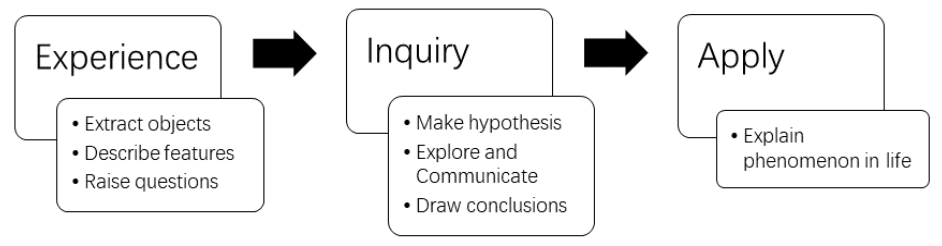

Figure 1 the contextual learning approach

The contextual learning approach consists of three phases, experience phase, inquiry phase and apply phase. In the experience phase of the contextual learning approach, learners will be 
motivated to participate in the activities in a unique way. By the use of $\mathrm{AR}$, leaners will be placed in a virtual-real combined environment including important information, and they will be inspired to raise questions through observing objects and their features in the environment. In the inquiry phase, AR is used to make it possible for learners to watch and control objects they can't see and interact directly in real life, such as the solar system and molecules in the air. This phase is an organic combination of exploration and explanation in the 5E model. We believe deeper exploration could be inspired by sharing thoughts about the phenomenon, so these two phases could be regarded as an upward spiral. AR can also be helpful in expression because the visual presentation can assist learners to describe their opinion more accurately. In the apply phase, learners use the conclusions to explain other cases in life. AR can be used to offer a framework for thinking.

\section{Method}

\subsection{Research Questions}

The research questions of this study are presented below.

Q1: Can the use of AR and the approach benefit students' construction of understandings about scientific concepts in a regular class?

Q2: Can the use of AR and the approach benefit students' improvement of skills about scientific literacy in a regular class?

Q3: Whether the use of the contextual learning approach contributes to supporting inquiry activities with AR in this class?

\subsection{Participants}

28 students in grade 5 and their science teacher in Chengdu, a city of Sichuan province in China, participated in this study. These students experienced other AR applications before this class to learn how to use the camera to capture special targets and interact with AR environments.

\subsection{Instruments}

The scale of the inquiry-based tasks analysis inventory (ITAI) was used to conduct an overall analysis of the whole class activities by two observers. And semi-structured interviews were implemented to explore how AR assist students in an inquiry.

ITAI was an instrument for evaluating science inquiry-based tasks in science. The researchers concluded four essential functions that inquiry-based tasks should serve are defined: (1) assisting in the construction of understandings about scientific concepts, (2) providing students opportunities to use inquiry process skills, (3) being conducive to establishing understandings about scientific inquiry, and (4) giving students opportunities to develop higher order thinking skills. ITAI was developed to judge whether inquiry-based tasks perform these functions well. By analyzing 53 inquiry-based tasks in the biology textbooks in Mainland China, this instrument showed (1) the inter-rater reliability reached $87.7 \%$, (2) the grading criteria have high discriminant validity, (3) the items possess high convergent validity, and (4) the Cronbach's alpha reliability coefficient reached 0.792.(Yang \& Liu, 2016a)

ITAI contains 22 items in 3 dimensions (Yang \& Liu, 2016b), which are shown in Table 1 below.

Table 1 items of scale of the inquiry-based tasks analysis inventory

\begin{tabular}{l|l} 
Dimensions & Items
\end{tabular}


Vol. 1, Issue 1, June 2019 Journal of Education, Innovation, and Communication (JEICOM) Pages 19- 30

\begin{tabular}{|c|c|}
\hline $\begin{array}{l}\text { Dimension 1: To assist in } \\
\text { the construction of understandings }\end{array}$ & $\begin{array}{l}\text { 1. Scientific concepts involved in this task are } \\
\text { consistent with the objectives of the lesson }\end{array}$ \\
\hline about scientific concepts & $\begin{array}{l}\text { 2. Understandings about the involved concepts } \\
\text { contribute to learning core ideas }\end{array}$ \\
\hline Dimension 2: in this task, & 3. Observing \\
\hline students are expected to use the & 4. Inferring \\
\hline following skills & 5. Measuring \\
\hline & 6. Communicating \\
\hline & 7. Classifying \\
\hline & 8. Predicting \\
\hline & 9. Controlling variables \\
\hline & 10. Defining operationally \\
\hline & 11. Formulating hypotheses \\
\hline & 12. Interpreting data \\
\hline & 13. Asking questions \\
\hline & 14. Formulating models \\
\hline $\begin{array}{l}\text { Dimension 3: The text of } \\
\text { this task reflects the following }\end{array}$ & $\begin{array}{l}\text { 15. Scientific inquiry all begin with a question, } \\
\text { but do not necessarily test a hypothesis }\end{array}$ \\
\hline $\begin{array}{l}\text { understandings about scientific } \\
\text { inquiry }\end{array}$ & $\begin{array}{l}\text { 16. There is no single set and sequence of steps } \\
\text { or methods followed in all inquiries }\end{array}$ \\
\hline & $\begin{array}{l}\text { 17. Inquiry procedures are guided by the } \\
\text { question asked }\end{array}$ \\
\hline & $\begin{array}{l}\text { 18. All scientists performing the same } \\
\text { procedures may not get the same results }\end{array}$ \\
\hline & 19. Inquiry procedures can influence results \\
\hline & $\begin{array}{l}\text { 20. Conclusions must be consistent with the } \\
\text { data collected }\end{array}$ \\
\hline & $\begin{array}{l}\text { 21. Scientific data are not the same as scientific } \\
\text { evidence }\end{array}$ \\
\hline & $\begin{array}{l}\text { 22. Explanations are developed from a } \\
\text { combination of collected data and what is already } \\
\text { known }\end{array}$ \\
\hline
\end{tabular}

Semi-structured interviews were used to examine if and how AR changed students' learning in the teacher's view. The outline of the interviews is shown below.

1) What do you know about AR and what characteristics do you think it has?

2) What functions does AR play in classroom activities?

3) If AR can't be used, how will you manage this class?

4) In what activities in the class is AR helpful to students?

5) How AR assist students in the activities?

6) What preparation should teachers do before using AR in class?

7) What should teachers do when students using AR in class?

8) What effects will the use of AR in class have on the growth of students? 
9) Do you have any suggestions for teachers preparing to use AR in class?

\subsection{AR Application Design}

In this study, the application, called Secrets of Rainbow, containing three main scenes is designed. It could run on Android devices with cameras and gyroscopes. This application was developed based on the Unity 3D engine and Vuforia SDK.

Secrets of Rainbow contains three main scenes: (1) Find Rainbow; (2) Time for Rainbow; and (3) Watch Rainbow Together. These scenes are designed and implemented to make inquiry activities in class more vivid and interactive.

1) Find Rainbow

Users can observe views before a rain, during a rain, and after a rain around by lifting the device to different directions with the gyroscope. There are four buttons at the bottom left of the screen, clouds, rain, go to watch rainbow and once again, which are clicked to change the virtual views presented. The main elements in this scene include clouds, raindrops, rainbow and setting sun. This scene shows the conditions for the rainbow to appear: (1) after a rain, (2) water vapour in the air and (3) setting sun.

2) Time for Rainbow

Users can explore the best time to watch a rainbow in this scene. By capturing a special card with the camera, the white little man, the sun and rainbow will be presented. Sliding on the scrollbar at the bottom can change the time and cause a change in the position of the sun and rainbow. Buildings will appear or disappear when the city button is clicked. The top right corner of the screen is the perspective of the little man, which can be changed by colliding and rotating the little man. This scene mainly shows the connection between the sun and the rainbow in position, implying the time of day when the rainbow can be seen.

3) Watch Rainbow Together

Users can explore the best location to watch a rainbow in this scene. By capturing two special cards with the camera, the white little man and the yellow little man with the water drop and the rainbow in their each perspective will be presented as shown in Figure 2. Moving one of the cards can change the yellow man's position and cause the position and size's changes of his rainbow. This scene mainly shows the location where the rainbow can be seen, implying why at some places we can see the rainbow and at some places we can't.

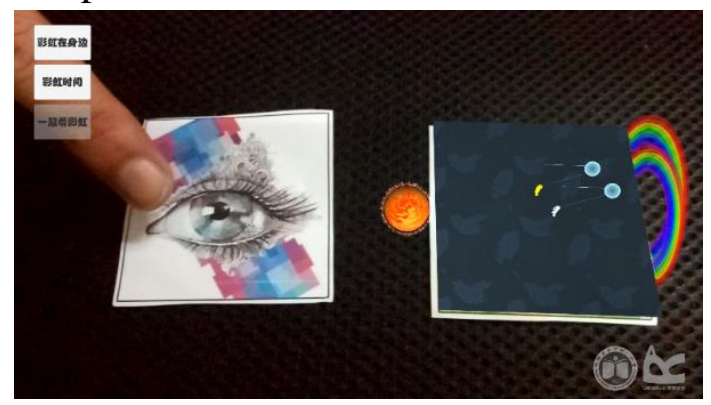

Figure 2 the application guides students explore location to watch rainbow

\subsection{Instructional Design}

In this study, a science lesson for fifth-grade students, also named "Secrets of Rainbow", containing some learning activities with mobile-based AR applications were designed. This lesson would be implemented after students learned the reflection, refraction, and dispersion of light as a unit supplement lesson. 
The basic goal of this lesson is to understand the conditions of the rainbow and the rainbow is always in the opposite direction of the sun. Inquiry activities were carried out to help students construct this knowledge by themselves, during which students needed to observe the views, raise their interesting questions, verify their hypothesis through the combination of a virtual and real environment. These inquiry activities are the core of this lesson and the reason for using AR technology. Rainbow is a charming meteorological landscape that requires special conditions to form that most of the students are interested in, and it can hardly be controlled by humans. The use of AR offers visible variables for the students to change and presents the corresponding phenomenon, which helps students know the principles about the rainbow and inspire them to take a closer look in real life if that happens.

In this lesson, every two students would have a tablet, so they could learn with the AR application together. Pairs of students should cooperate in integrating with cards and application, analyzing what they observe, and recording their findings on the list given by the teacher.

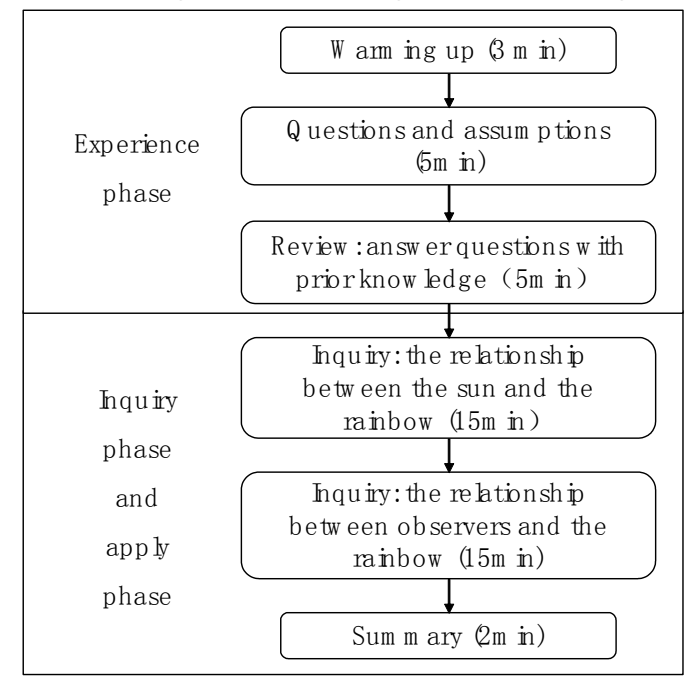

Figure 3 structure of the lesson

The basic structure of this lesson is shown in Figure 3. The mobile-based AR application is used in warming up and two inquiry activities. The first 3 minutes of the lesson is used in warming up, in that step teachers present pictures of the rainbow as well as lead students to use AR application experience the form of a rainbow and observe rainbow views as shown in Figure 4. In the next five minutes, students shared their findings in the AR observation and raise questions about rainbow according to their finding under the teacher's guide. After that, they asked questions based on their prior knowledge. Students solved why there are seven colours in the rainbow and why the colours of the rainbow always presented from red to purple. Then, they wanted to explore when and where to watch the rainbow through inquiry activities.

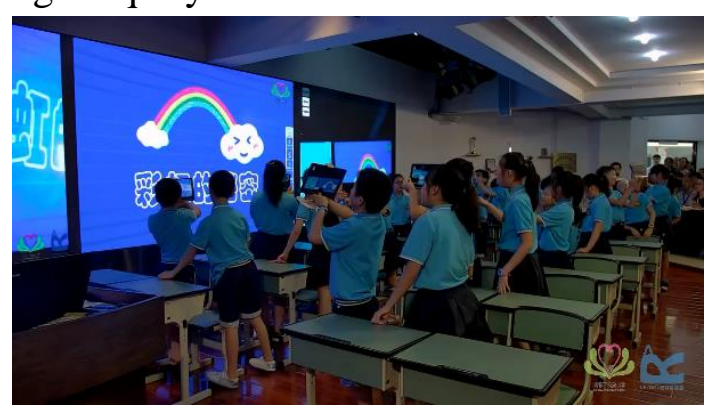

Figure 4 students were looking for rainbow with $\mathrm{AR}$ 
Vol. 1, Issue 1, June 2019 Journal of Education, Innovation, and Communication (JEICOM) Pages 19- 30

There are four steps in each of the inquiry activities as shown in Figure 5. The teacher would give a question students raised in step 2 and offer several different choices. After students choosing one, the whiteboard system would present the statistics on the number of people selected for every option. Then the teacher introduced the corresponding AR application scene to students and assist them to make the inquiry plan.

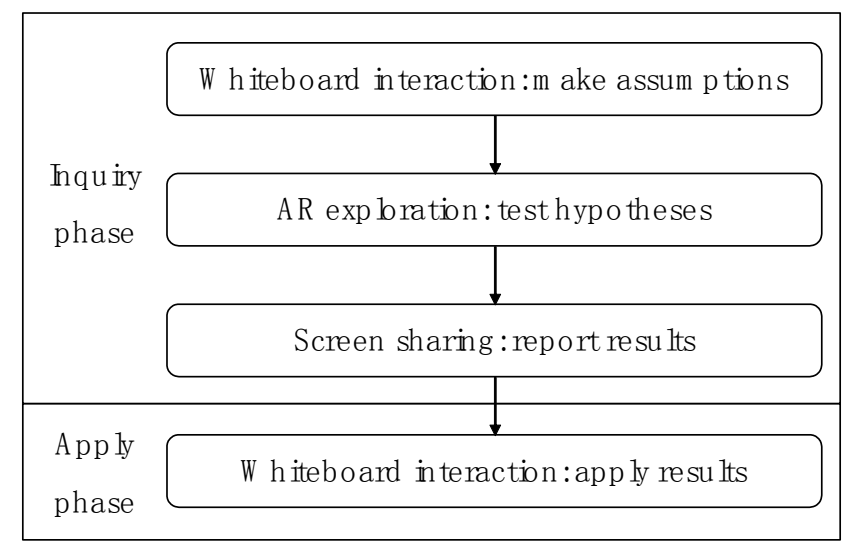

Figure 5 structure of the inquiry activities

Exploration with AR application was the core of each inquiry activity. Students needed to observe, guess and discuss independently and reach agreement in groups as shown in Figure 6. Nearly 6 minutes later, a pair of students would be asked to share their inquiry process and results through the link between their tablet and the whiteboard in the classroom. Other students and the teacher would discuss their results and conclude the rules after their presentation. When students determined their conclusion, the teacher would list several situational questions for students and help them to understand and apply the conclusions.

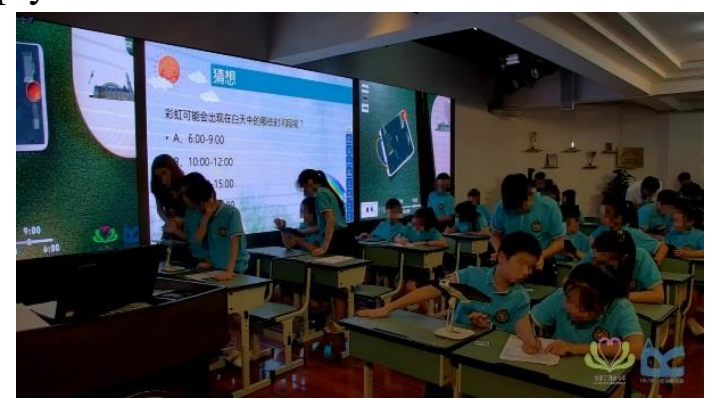

Figure 6 students were exploring best time to observe rainbow

At the end of this class, the teacher led students to recall what they had learned in this class and inspired them to explore more about the relevant phenomenon in real life.

\section{Results}

Two observers evaluated the class based on ITAI, and an interview with the teacher was conducted after we got the observation results to collect the teacher's thoughts about the integration of AR and teaching.

\subsection{Results of observation}

The two observers judged every item according to the content and guidance of ITAI, and there are 15 abilities they both agree involved in this lesson as shown in Table 2.

Table 2 the unanimous items of observers

\begin{tabular}{|c|c|}
\hline Dimension & Items \\
\hline
\end{tabular}


Vol. 1, Issue 1, June 2019 Journal of Education, Innovation, and Communication (JEICOM) Pages 19- 30

\begin{tabular}{|c|c|}
\hline \multirow{2}{*}{$\begin{array}{l}\text { Dimension 1: To } \\
\text { assist in the construction } \\
\text { of understandings about } \\
\text { scientific concepts }\end{array}$} & $\begin{array}{l}\text { 1. Scientific concepts involved in this task are consistent } \\
\text { with the objectives of the lesson }\end{array}$ \\
\hline & $\begin{array}{l}\text { 2. Understandings about the involved concepts contribute } \\
\text { to learning core ideas }\end{array}$ \\
\hline \multirow{7}{*}{$\begin{array}{l}\text { Dimension 2: in } \\
\text { this task, students are } \\
\text { expected to use the } \\
\text { following skills }\end{array}$} & 3. Observing \\
\hline & 4. Communicating \\
\hline & 5. Predicting \\
\hline & 6. Controlling variables \\
\hline & 7. Formulating hypotheses \\
\hline & 8. Asking questions \\
\hline & 9. Formulating models \\
\hline \multirow{6}{*}{$\begin{array}{l}\text { Dimension 3: this } \\
\text { task reflects the } \\
\text { following understandings } \\
\text { about scientific inquiry }\end{array}$} & $\begin{array}{l}\text { 10. Scientific inquiry all begin with a question, but do not } \\
\text { necessarily test a hypothesis }\end{array}$ \\
\hline & 11. Inquiry procedures are guided by the question asked \\
\hline & $\begin{array}{l}\text { 12. All scientists performing the same procedures may not } \\
\text { get the same results }\end{array}$ \\
\hline & 13. Inquiry procedures can influence results \\
\hline & 14. Scientific data are not the same as scientific evidence \\
\hline & $\begin{array}{l}\text { 15. Explanations are developed from a combination of } \\
\text { collected data and what is already known }\end{array}$ \\
\hline
\end{tabular}

In the dimension of construction of understandings about scientific concepts, both of the observers agreed that the concepts referred to in the objectives of this lesson were the conclusions of these inquiry tasks, and these concepts are components of core ideas described in the national standards. The directions of light propagations and the compositions of light are the concepts students required to manage during 5 to 6 grades in China's primary school. And this lesson containing the inquiry activities were carried out to assist students to construct these concepts based on examples from real life.

In the dimension of scientific skills, observing, communicating, predicting, controlling variables, formulating hypotheses, asking questions and formulating models are 7 skills that were considered in this lesson by observers. Students were required to observe in the virtual and reality combined environment, communicate with their pair to cooperate, predict by choosing answers on the whiteboard, control variables in inquiry where to watch the rainbow, formulate hypotheses before the operation with AR application, ask research questions and formulate models about the form of a rainbow. One of the observers thought classifying also exist in this lesson, for students needed to distinguish among different phenomenon. But the other observer thought there was no clear classification.

In the dimension of understandings about scientific inquiry, both of the observers believed this lesson was helpful for students to acquire deeper understandings about the science inquiry process. The ignorance in this lesson was about concluding based on data collected. Observers guessed it was because the lesson aimed to apply some knowledge in explaining real situations, so this lesson focused on observing and assuming more.

\subsection{Results of teacher interview}


In the interview with the teacher, questions mainly focused on why teacher choose to use AR in this lesson and how AR assist students in dimensions of ITAI. The teacher proposed to use AR to explore the rainbow and participated in the design of the application. And the teacher was also one of the instructional designers of this lesson.

The teacher thought that the advantage of AR in teaching or learning lied in its ability to promote students' intuitive feelings through the interaction with the combination of virtual objects and real environment. Using AR to present rainbow, which was an interesting mystery in students' opinion, could make students feel pleased and positive and let them connect knowledge with interesting life phenomenon.

As for skills in inquiry, the teacher claimed that AR has a strong ability to express the situations, which was able to highlight the important variables and their features in the phenomenon so that students could pay attention to the connection between variables they have not noticed in real life. And the well-designed AR application helped organize the whole inquiry process in observation, hypothesis, exploration, and conclusion. Otherwise, AR was good at controlling variables for it simplifies the complex phenomenon to prominent the objects related to the lesson's basic goals. Most importantly, the use of AR also helped students develop the ability of autonomous learning.

In the group task in this lesson, the teacher explained that pair works were regular in science class to help students' expression, communication, and construction. Students in a pair could learn from each other and share the pressure of the task.

To use AR well in class, teachers needed to do more preparation and change their roles in class. Before class, teachers should integrate AR in the teaching process well to avoid using technology for its own sake. And in class, teachers' work was to assist students, helping promote the process of activities, test students' learning results, and inspire students to explore independently. Although there were more efforts, students' performances would bring teachers a high sense of achievement.

\section{Discussion and conclusion}

In this study, an AR application was specially designed and implemented to create a virtualreality combined environment for students taking an optical inquiry task about the rainbow in grade 5. Moreover, a mixed methods research approach was used to test the contextual learning approach based on AR. The experimental results revealed that using AR in this lesson can assist in the construction of understandings about scientific concepts, provide students opportunities to use inquiry process skills, and develop students' higher order thinking skills. Furthermore, by interviewing the teacher, we found AR plays complex roles in inquiry activities and a matched instructional approach is necessary for ensuring the integration between AR and learning.

In this study, the contextual learning approach was the core of the learning process, by which the environment created by AR inspires students' observation, exploration, and expression successfully. In the experience phase of this lesson, students were touched by the formation and beauty of the rainbow, when they extracted the objects and their features related to the rainbow. Then their deep feelings engaged them to raise more questions and make hypothesises. The vivid presentation based on AR is indeed able to arouse students' interests and promote them to construct knowledge (Takahashi et al., 2013; H. T. Zimmerman et al., 2016). In the inquiry phase, AR application was used to help come to a consistent conclusion, when the teacher asked one group of students showed their exploration and shared their results after each exploration activity. As Yoon 
and Wang (2014) once discovered, AR could promote more expressions and consistency in collaboration. In the apply phase, explaining other cases in life with AR application promoted concept understandings and knowledge model constructions. The probable reason is that coordinating images in AR with actual samples enhanced students' understanding of concepts(Heather Toomey Zimmerman et al., 2015).

It has been clear that AR has the potential to create abundant learning environments, and the contextual learning approach has played a vital role in integrating AR with inquiry activities properly. In the future, how to use AR properly in teaching and learning deserves more continuous attention.

\section{Acknowledgement}

The lesson in this study was implemented in Jitou primary school in Chengdu, Sichuan province, China. Several teachers in the school helped us with our research, especially Guangxi Li, the teacher who taught with AR and interviewed with us. Our work is supported by the National Natural Science Foundation of China (61602043) and 2019 Comprehensive Discipline Construction Fund of Faculty of Education, Beijing Normal University.

\section{References}

Asai, K., Sugimoto, Y., \& Billinghurst, M. (2010). Exhibition of lunar surface navigation system facilitating collaboration between children and parents in Science Museum. Paper presented at the Proceedings - VRCAI 2010, ACM SIGGRAPH Conference on Virtual-Reality Continuum and Its Application to Industry.

Azuma, R., Baillot, Y., Behringer, R., Feiner, S., Julier, S., \& Macintyre, B. (2001). Recent advances in augmented reality. Computer Graphics and Applications, IEEE, 21(6), 34-47. doi:10.1109/38.963459

Bruns, E., Brombach, B., Zeidler, T., \& Bimber, O. (2007). Enabling Mobile Phones To Support Large-Scale Museum Guidance. MultiMedia, IEEE, 14(2). doi:10.1109/MMUL.2007.33

Bybee, R. W. (2014). The BSCS 5E instructional model: Personal reflections and contemporary implications.(Guest Editorial). Science and Children, 51(8), 10.

Carmigniani, J. (2011). Augmented reality technologies, systems and applications. Multimedia tools and applications, 51(1), 341-377.

Chang, S.-C., \& Hwang, G.-J. (2018). Impacts of an augmented reality-based flipped learning guiding approach on students' scientific project performance and perceptions. Computers \& Education, 125, 226-239. doi:10.1016/j.compedu.2018.06.007

Chen, C. H., Chou, Y. Y., \& Huang, C. Y. (2016). An Augmented-Reality-Based Concept Map to Support Mobile Learning for Science. Asia-Pacific Education Researcher, 25(4), 567-578. doi:10.1007/s40299-016-0284-3

Dunleavy, M., Dede, C., \& Mitchell, R. (2009). Affordances and Limitations of Immersive Participatory Augmented Reality Simulations for Teaching and Learning. Journal of Science Education and Technology, 18(1), 7-22. doi:10.1007/s10956-008-9119-1

Falk, J. H., \& Dierking, L. D. (2000). Learning from museums: visitor experiences and the making of meaning. In (Vol. 15). Portland: Ringgold Inc.

Kusmayadi, T. A., Riyadi, Kartikaningtyas, V., \& Kusmayadi, T. A. (2017). Contextual Approach with Guided Discovery Learning and Brain Based Learning in Geometry Learning. Journal of Physics: Conference Series, 895. doi:10.1088/1742-6596/895/1/012024 
Vol. 1, Issue 1, June 2019 Journal of Education, Innovation, and Communication (JEICOM) Pages 19- 30

Liu, Y., \& Wang, Y. (2009). AR-View: An augmented reality device for digital reconstruction of Yuangmingyuan. In (pp. 3-7).

Miyashita, T., Meier, P., Tachikawa, T., Orlic, S., Eble, T., Scholz, V., . . . Lieberknecht, S. (2008). An Augmented Reality museum guide. In (pp. 103-106).

NASA. (2008). 5Es Overview: "The 5E instructional model". Retrieved from http://www.nasa.gov/audience/foreducators/nasaeclips/5eteachingmodels/index.html

Rt, A. (1997). A survey of augmented reality. Presence, 6(4), 355-385.

Takahashi, T. B., Takahashi, S., Kusunoki, F., Terano, T., \& Inagaki, S. (2013). Making a HandsOn Display with Augmented Reality Work at a Science Museum. In (pp. 385-390).

Wernhuar, T., Yu-Sheng, L., Chiu-Pin, L., \& Kuo-Liang, O. (2016). Development of a Lunar-Phase Observation System Based on Augmented Reality and Mobile Learning Technologies. Mobile Information Systems, 2016. doi:10.1155/2016/8352791

Wu, P.-H., Hwang, G.-J., Yang, M.-L., \& Chen, C.-H. (2018). Impacts of integrating the repertory grid into an augmented reality-based learning design on students' learning achievements, cognitive load and degree of satisfaction. Interactive Learning Environments, 26(2), 221234. doi:10.1080/10494820.2017.1294608

Yang, W., \& Liu, E. (2016a). Development and Validation of an Instrument for Evaluating InquiryBased Tasks in Science Textbooks. International Journal of Science Education, 38(18), 2688-2711. doi:10.1080/09500693.2016.1258499

Yang, W., \& Liu, E. (2016b). Scale of the Inquiry-based Tasks Analysis Inventory. PsycTESTS. doi:10.1037/t64864-000

Yoon, S. A., \& Wang, J. (2014). Making the Invisible Visible in Science Museums through Augmented Reality Devices. TechTrends: Linking Research and Practice to Improve Learning, 58(1), 49-55. doi:10.1007/s11528-013-0720-7

Zimmerman, H. T., Land, S. M., \& Jung, Y. J. (2016). Using augmented reality to support children's situational interest and science learning during context-sensitive informal mobile learning. Advances in Intelligent Systems and Computing, 406, 101-119. doi:10.1007/978-3319-26518-6_4

Zimmerman, H. T., Land, S. M., McClain, L. R., Mohney, M. R., Choi, G. W., \& Salman, F. H. (2015). "Tree Investigators": Supporting Families' Scientific Talk in an Arboretum with Mobile Computers. International Journal of Science Education, Part B: Communication and Public Engagement, 5(1), 44-67. doi:10.1080/21548455.2013.832437 